\title{
Development of Composite Solid Fuel from Charcoal and Saw Dust for Maximum Emission Reduction
}

\author{
Mamudu Abbas*, Mamudu Yahaya and Olafuyi Olalekan \\ Department of Chemical Engineering and Department of Petroleum Engineering, University of Benin, Benin City, Nigeria
}

\begin{abstract}
In consideration to the various impacts of charcoal and sawdust burning especially in the indoor fires in the developing countries. A charcoal-based and sawdust composite solid fuel has been developed to immensely reduce gaseous emissions, and as well minimize pollution from these sources. The formulations were made using clay (kaolinite) solution (1:2 of clay: water), sawdust and solid pulverized charcoal. Different mounts of the charcoal and sawdust were mixed with a fixed known amount of clay solution and a total of six formulations were made. $200 \mu \mathrm{m}$ sieve, $500 \mathrm{ml}$ beaker and pdt-crowcon gasman single-trace gas (CO) analyzers were all used in the solution formulation and emission analysis. The results show that the fuel-types which were produced from a mixture of the solid fuels and clay solution yield its minimum emission for a formulation of 1:1 of fuel (charcoal or sawdust): clay solution (1:2 of clay: water) by mass fraction. The results show a consistent pattern of emission reduction exhibited by the composite charcoal based fuels. The combustion of sawdust and its formulations follow a trend which is approximately equivalent to that of charcoal but with a higher release of emission. This higher release of emission from sawdust- based composite fuels show that sawdust is a better burner than charcoal. The addition of the clay content significantly contributes in channeling the routes of release of some of the compounds in the fuels to accompany the ash residue rather than as gaseous emissions. Therefore, the advantages include among others high gaseous emission reduction.
\end{abstract}

Keywords: Beaker; Charcoal; Clay; Coal; Composite solid fuels; Emission measurement; Formulation; Kaolinite; Pdt-crowcon gasman single trace gas (CO) analyzer; Sieve; Sawdust

\section{Introduction}

More than half of the world's population still depends on fuel sources that are inefficient, highly polluting and unhealthy. These fuels which are referred to as solid fuels include biomass (wood, animal dung and crop wastes) and coal. People who use these fuel sources burn them in open fires or simple stoves that release most of the smoke into their home, resulting in indoor air pollution that threatens the health of household members, especially women and young children [1]. These pollutants, called solid-fuel "smoke" include respirable particles, carbon monoxide, oxides of nitrogen and sulfur, benzene, formaldehyde, 1,3-butadiene and polyaromatic compounds such as benzo(a)pyrene [2]. In households with limited ventilation (as is common in many developing countries), exposures experienced by household members, particularly women and young children who spend a large proportion of their time indoors, have been measured to be many times higher than World Health Organization (WHO) guidelines and national standards $[2,3]$.

In Nigeria, considering the fact that the country has been experiencing inefficient and insufficient power supply, the use of varieties of locally made indoor direct-fired cooking stoves, lanterns and candles for space lighting are inevitable. Furthermore, considering the location of the country around the equator on $6^{\circ} \mathrm{N} 5^{\circ} \mathrm{E}$ and over the rain forest region. The environment is prone massive breeding for varieties of mosquitoes. Hence, the use of numerous insecticides such as aerosol spray-type of repellent and smoke-producing mosquito coils. In most household over the Midwestern region of Nigeria, the use of smoke producing heating and lighting devices as well as mosquito coils produce gases and particular matter that contribute to indoor air borne related diseases. The presence of these pollutants in indoor air could lead to episodes of high mortality and morbidity rates over the region $[2,3]$.

The interest in forest conservation is largely due to the important role forests play in the global carbon cycle as a mean of reducing global emissions of greenhouse gasses [4-6]. However, in the last few decades, apart from the deforestation in Africa and Asia, South American forests have continued to record large losses of covered area [7]. The rich biodiversity of these tropical forests continues to be in danger of deforestation despite initiatives from Latin American countries, such as the increase of protected areas [8]. In the region of Piura in Peru, there are 389,685 homes of which $55.81 \%$ use firewood and charcoal daily as domestic fuel according to the Istituto Nacional de Estadística del Perú - INEI [9]. The Ministry of Environment (1977) states that this material coming from the cutting of dry forest areas characteristic of the region and protected areas such as the Northwest Biosphere Reserve. This situation is compounded by the emission of greenhouse gasses as a result of open indiscriminate burning of wood waste (sawdust, chips and shavings among others) representing approximately $42 \%$ of the production from sawmills, which is equivalent to burning 861.84 $\mathrm{m}^{3}$ of wood waste per year in the region according to the INEI [1012]. Following a premise from United Nations [7], greater efforts and innovative approaches are required to reduce the loss of biodiversity in ecosystems such as forests, and to lower $\mathrm{CO}$ emissions to curb climate change [13].

In developing countries, especially in rural areas, 2.5 billion people rely on biomass, such as fuel wood, charcoal, agricultural waste and animal dung, to meet their energy needs for cooking [14]. In many countries, these resources account for over $90 \%$ of household energy consumption [14]. In the absence of new policies, the number of people

*Corresponding author: Mamudu Abbas, Department of Chemical Engineering and Department of Petroleum Engineering, University of Benin, Benin City, Nigeria, Tel: +2348039351412; E-mail: abbasagim@yahoo.com

Received February 23, 2016; Accepted April 04, 2016; Published April 08, 2016

Citation: Abbas M, Yahaya M, Olalekan O (2016) Development of Composite Solid Fuel from Charcoal and Saw Dust for Maximum Emission Reduction. J Environ Anal Toxicol 6: 365. doi:10.4172/2161-0525.1000365

Copyright: ( 2016 Abbas M, et al. This is an open-access article distributed under the terms of the Creative Commons Attribution License, which permits unrestricted use, distribution, and reproduction in any medium, provided the original author and source are credited. 
relying on biomass will increase to over 2.6 billion by 2015 and to 2.7 billion by 2030 because of population growth [14]. That is, one-third of the world's population will still be relying on these fuels. There is evidence that, in areas where local prices have adjusted to recent high international energy prices, the shift to cleaner, more efficient use of energy for cooking has actually slowed and even reversed. Use of biomass is not in itself a cause for concern. However, when resources are harvested unsustainably and energy conversion technologies are inefficient, there are serious adverse consequences for health, the environment and economic development [14]. About 1.3 million people mostly women and children die prematurely every year because of exposure to indoor air pollution from biomass [14].

In consideration to the environmental pollution challenges facing most of the Sub-Sahara African nations, especially, Nigeria, it becomes very important to arrest these pollutants from their sources. This study is geared towards arresting pollutants from solid fuels. This is to be achieved through the following: Making clay solution (clay: water), formulating composite fuels of different ratios with the clay solution and testing the formulations for maximum emission-reduction. In summary, the formulations were made using clay (kaolinite) solution (1:2 of clay: water), saw dust and solid pulverized charcoal. Different mounts of the charcoal and saw dust was mixed with a fixed known amount of clay solution and a total of six formulations were made. $200 \mu \mathrm{m}$ sieve, $500 \mathrm{ml}$ beaker and pdt-crowcon gasman single trace gas (CO) analyzers were all used in the solution formulation and emission analysis. The pure charcoal saw dust and formulated samples were all tested at $400^{\circ} \mathrm{C}$

The main aim of this research work is to produce composite solid fuels from charcoal and saw dust with reduced emission and thereby minimize pollution from such sources.

\section{Samples Formulation and Emission Measurement}

A brief description of the composite fuel samples formulation and emission analysis is given in this section.

\section{Materials used}

Clay (kaolinite), water, kaolinite solution (1:2 of clay: water), sawdust, charcoal, $200 \mu \mathrm{m}$ sieve, $500 \mathrm{ml}$ beaker and pdt-crowcon gasman single trace gas $(\mathrm{CO})$ analyzers.

\section{Sample preparation and formulation}

For this study, commonly available charcoal and saw dust in the rural areas of Nigeria were used. The formulated charcoal and saw dust fuels were prepared using kaolinite clay solution saw dust and solid pulverized charcoal. Clay-sand mixture was dissolved in water, stirred continuously until the clay components of the mixture were in solution. The solution was decanted through a $200 \mu \mathrm{m}$ sieve into a 500 $\mathrm{ml}$ beaker to remove suspended particles and kept to allow the fine clay particle settle. After 48 hours clear water was decanted off leaving very fine clay which was dried in an oven maintained at $250^{\circ} \mathrm{C}$ for 2 hours. The dried clay was pulverized, measured, mixed with distilled water and made into solutions. Different amounts of the clay solution were mixed with a fixed known amount of pure charcoal and saw dust to produce the several formulated coal samples [15].

Six formulations of the composite charcoal and saw dust were performed using the clay-water mixtures. The clay-water mixtures was of ratio 1:2.5 and the mixtures or simply clay solutions was then added to the varying amounts of charcoal and saw dust to form 6 samples of different compositions. The different charcoal to clay formulated produced were 1:1, 1.5:1 and 2:1 designated as samples $C_{1}, C_{2}$ and $C_{3}$ respectively. In a similar fashion, the saw dust to clay-solution was produced and they were designated as $\mathrm{S}_{1}, \mathrm{~S}_{2}$ and $\mathrm{S}_{3}$. The mixtures of charcoal saw dust and clay solution formed pastes which were then placed in crucibles lined with filter paper and kept in an oven at $250^{\circ} \mathrm{C}$ for 2 hours until the mixture was dry. The lumps were then left to cool.

\section{Emission measurement}

In this study, carbon monoxide was examined from the burning of the pure and the formulated charcoal-clay and saw dust-clay fuel samples. The instrument applied for sampling was the model pdtcrowcon gasman single trace gas analyzers. The instrument began with testing all the batteries to ensure good power supply, the red and blue alarm LEDs, sounder and internal vibrator alert. The analyzers were calibrated for ranges, zero and span checks, temperature and pressure correction factors before sampling began to rectify drifts in measurements. A detailed description of the CO analyzer operation is given by the pdt-crowcon gasman instruments user's manual.

Sampling was conducted from the stack of the furnace where the samples were burnt. An inlet probe fitted to about the middle of the length of the smoke stack was connected to a manifold of equal internal diameter. The outlet was connected to the sample inlet of the trace gas analyzer. During sampling, a particular temperature and burning period were maintained while the sample types were varied.

\section{Procedure}

Following the assembly set-up, combustion for emission analysis began. Starting with the pure samples and followed by the formulated composite charcoal-clay and saw dust-clay samples.

For each sample run, 5 grams of the crushed solid fuel sample was placed in a crucible and kept in the furnace set to a temperature of $400^{\circ} \mathrm{C}$ to burn. This was performed for 20 minutes to allow for complete burning of each sample. During the combustion, emitted gases were measured continuously by the gas analyzers and the concentration was being recorded every 60 seconds.

\section{Results and Discussion}

This section presents the results of the analysis of gaseous emissions from combustion of the pure and formulated samples.

Charcoal and saw dust burning in domestic heaters usually operates at elevated temperature of about $400^{\circ} \mathrm{C}$ and above, however, combustion at $400^{\circ} \mathrm{C}$ is most efficient as less emission is released over the same burning duration [15] and as a result the combustion, tests were conducted at $400^{\circ} \mathrm{C}$. All the formulated solid fuel samples follow the same emission distribution growth behavior. The test results show that sample burning generates an initially high pollutant concentration followed by a sudden drop, then a rise and fall in a sinusoidal form but with decreasing intensity of the wave peak. The pattern occurs until the wave peaks generated flattens out. There is a sudden initial rise in the gas concentration reaching its peak within 5 minutes of start time. Thereafter, the concentration declines steadily and stabilizes on a particular value for the operating condition.

Table 1 shows the values of the concentrations (ppm) and time (m) of the samples indicating the temporal variation of CO emission levels from the pure and the formulated charcoal samples. While Table 2 depicts the values of the concentrations (ppm) and time (m) of the samples indicating the temporal variation of $\mathrm{CO}$ emission levels from the pure and the formulated sawdust samples. 


\begin{tabular}{|c|c|c|c|c|}
\hline \multirow[b]{2}{*}{$\begin{array}{l}\text { Time, } \\
\text { mins }\end{array}$} & \multirow[b]{2}{*}{$\begin{array}{c}\text { Pure Sample, } \\
\text { ppm }\end{array}$} & \multicolumn{3}{|c|}{ Charcoal: Clay Sample } \\
\hline & & $\begin{array}{l}\text { 2:1 Solution, } \\
\text { ppm }\end{array}$ & $\begin{array}{c}\text { 1.5:1 Solution, } \\
\text { ppm }\end{array}$ & $\begin{array}{c}\text { 1:1 Solution, } \\
\text { ppm }\end{array}$ \\
\hline 0.5 & 28 & 20 & 12 & 12 \\
\hline 1.5 & 49 & 35 & 12 & 18 \\
\hline 2.5 & 55 & 43 & 12 & 18 \\
\hline 3.5 & 63 & 51 & 18 & 28 \\
\hline 4.5 & 80 & 61 & 20 & 12 \\
\hline 5.5 & 55 & 45 & 15 & 9 \\
\hline 6.5 & 50 & 50 & 13 & 10 \\
\hline 7.5 & 45 & 36 & 12 & 9 \\
\hline 8.5 & 39 & 39 & 10 & 7 \\
\hline 9.5 & 42 & 37 & 9 & 6 \\
\hline 10.5 & 37 & 32 & 5 & 7.7 \\
\hline 11.5 & 43 & 33 & 7 & 7 \\
\hline 12.5 & 37 & 30 & 6 & 6 \\
\hline 13.5 & 35 & 34 & 7 & 7 \\
\hline 14.5 & 36 & 27 & 7 & 7 \\
\hline 15.5 & 37 & 23 & 5 & 6 \\
\hline 16.5 & 33 & 22 & 7.5 & 7.5 \\
\hline 17.5 & 30 & 23 & 5 & 7.5 \\
\hline 18.5 & 29 & 21 & 7 & 6 \\
\hline 19.5 & 27 & 23 & 6 & 6 \\
\hline 20.5 & 28 & 21 & 7 & 5 \\
\hline 21.5 & 26 & 19 & 5 & 5 \\
\hline 22.5 & 23 & 19 & 5 & 4 \\
\hline 23.5 & 22 & 20 & 3 & 6 \\
\hline 24.5 & 23 & 18 & 4 & 3 \\
\hline 25.5 & 21 & 19 & 5 & 5 \\
\hline 26.5 & 20 & 17 & 4 & 2.5 \\
\hline 27.5 & 17 & 17 & 5 & 4 \\
\hline 28.5 & 16 & 16 & 4 & 2.5 \\
\hline 29.5 & 16.5 & 15.5 & 2.5 & 2.5 \\
\hline
\end{tabular}

Table 1: Shows the values of the concentrations $(\mathrm{ppm})$ and time $(\mathrm{m})$ readings of the samples during combustion.

The contribution of clay incorporated in charcoal and saw dust for indoor heating has some considerable advantages over pure charcoal and saw dust as seen on Figures 1 and 2. The advantages include high emission reduction and a highly deadly pollutant emission is to a significant extent reduced in the rate during burning. In as much as the addition of clay to pure charcoal and saw dust has an effect on the reduction of emissions, a proportional solid fuel: clay solution trend indicates a limit to the addition of clay. The decrease in emissions of the various gases may be attributed to a repression of some particular minerals within the composite coal that might have possibly been transformed into solid which are embedded in the ash during combustion. The suspension of the minerals from being oxidized maybe attributed to the less release of the pollutant gases. The solution of 1:2 of clay: water, formulated into a composite of 1:1 of pure charcoal: clay solution and pure saw dust: clay solution produces the solid fuel-type with the best pollutants emission rates reduction. The addition of the clay content has only contributed in channeling the routes of release of some of the compounds in the fuels to accompany the ash residue rather than as gaseous emissions.

Figure 1 shows temporal variation of $\mathrm{CO}$ emission levels from the pure and the formulated charcoal samples. The $\mathrm{CO}$ emitted during the combustion of charcoal and the formulated samples show several erratic peaks throughout the burning but towards the last minutes of the combustion time, the concentrations of the pure charcoal and the sample, $\mathrm{C}_{3}$, eventually become approximately equivalent. A similar situation is observed for the other two samples but a lower concentration. This study has shown a consistent pattern of emission reduction exhibited by the composite charcoal based fuels. Figure 2 shows temporal variation of $\mathrm{CO}$ emission levels from the pure and the formulated sawdust samples.

The combustion of saw dust and its formulations follow a trend which is approximately equivalent to that of charcoal but with a higher release of emission. This higher release of emission from saw dust- based composite fuels shows that saw dust is a better burner than charcoal.

The health of the public can be adversely affected by the smoke created from wood burning which can easily be inferred from gaseous emission analysis of solid fuel combustion in Figures 1 and 2. The pollutants include carbon monoxide, fine particles and other chemical compounds such as oxides of nitrogen and a range of organic compound. These pollutants can cause breathing difficulties even at relatively low levels, especially for young children, the elderly and people who are already suffering from respiratory conditions such as asthma $[16,17]$. The gaseous emission results of the formulated composite charcoal and sawdust samples designated $\mathrm{C}_{1}$ and $\mathrm{S}_{1}$ have shown that these pollutants (carbon monoxide) from these sources can be immensely arrested by the use of clay (kaolinite).

The negative impact of biomass energy on the daily lives of populations (especially women and children) in the poorest parts of the developing world cannot be underestimated. Furthermore, evidence would strongly suggest that the persistent widespread use of biomass energy largely depends on the factors of access in Africa, affordability and pricing policies in Indonesia, coal in China and LPG in some countries.

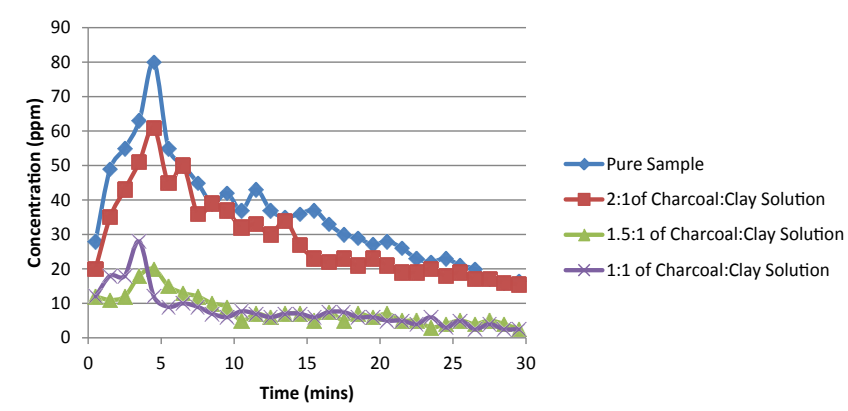

Figure 1: Shows temporal variation of $\mathrm{CO}$ emission levels from the pure and the formulated charcoal samples.

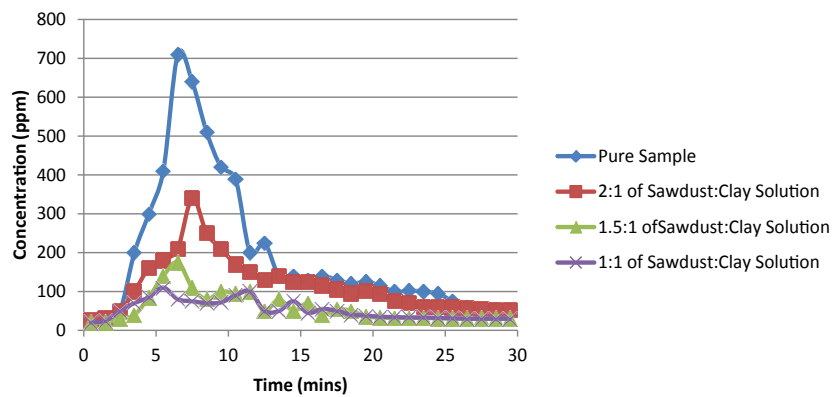

Figure 2: Shows temporal variation of $\mathrm{CO}$ emission levels from the pure and the formulated sawdust samples. 
Citation: Abbas M, Yahaya M, Olalekan O (2016) Development of Composite Solid Fuel from Charcoal and Saw Dust for Maximum Emission Reduction. J Environ Anal Toxicol 6: 365. doi:10.4172/2161-0525.1000365

Page 4 of 4

\begin{tabular}{|c|c|c|c|c|}
\hline \multirow[b]{2}{*}{$\begin{array}{l}\text { Time, } \\
\text { mins }\end{array}$} & \multirow[b]{2}{*}{$\begin{array}{c}\text { Pure Sample, } \\
\text { ppm }\end{array}$} & \multicolumn{3}{|c|}{ Sawdust: Clay Sample } \\
\hline & & $\begin{array}{c}\text { 2:1 Solution, } \\
\text { ppm }\end{array}$ & $\begin{array}{c}\text { 1.5:1 Solution, } \\
\text { ppm }\end{array}$ & $\begin{array}{c}\text { 1:1 Solution } \\
\text { ppm }\end{array}$ \\
\hline 0.5 & 20 & 25 & 20 & 20 \\
\hline 1.5 & 30 & 30 & 20 & 25 \\
\hline 2.5 & 50 & 50 & 30 & 50 \\
\hline 3.5 & 200 & 100 & 40 & 70 \\
\hline 4.5 & 300 & 160 & 85 & 85 \\
\hline 5.5 & 410 & 180 & 140 & 110 \\
\hline 6.5 & 710 & 210 & 175 & 80 \\
\hline 7.5 & 640 & 240 & 110 & 75 \\
\hline 8.5 & 510 & 250 & 80 & 70 \\
\hline 9.5 & 420 & 210 & 100 & 72 \\
\hline 10.5 & 390 & 170 & 95 & 90 \\
\hline 11.5 & 200 & 150 & 100 & 100 \\
\hline 12.5 & 225 & 130 & 50 & 50 \\
\hline 13.5 & 140 & 140 & 80 & 50 \\
\hline 14.5 & 140 & 125 & 50 & 75 \\
\hline 15.5 & 130 & 125 & 70 & 45 \\
\hline 16.5 & 140 & 115 & 40 & 55 \\
\hline 17.5 & 130 & 105 & 55 & 50 \\
\hline 18.5 & 120 & 95 & 50 & 40 \\
\hline 19.5 & 125 & 102 & 36 & 38 \\
\hline 20.5 & 115 & 93 & 33 & 35 \\
\hline 21.5 & 100 & 75 & 32 & 34 \\
\hline 22.5 & 102 & 71 & 32 & 33 \\
\hline 23.5 & 100 & 60 & 32 & 33 \\
\hline 24.5 & 95 & 60 & 31 & 32 \\
\hline 25.5 & 75 & 59 & 30.5 & 31 \\
\hline 26.5 & 60 & 58 & 30 & 30 \\
\hline 27.5 & 55 & 55 & 30 & 30 \\
\hline 28.5 & 53 & 53 & 30 & 30 \\
\hline 29.5 & 52 & 52 & 30 & 30 \\
\hline
\end{tabular}

saw dust and its formulations follow a trend which is approximately equivalent to that of charcoal but with a higher release of emission. This higher release of emission from saw dust- based composite fuels shows that saw dust is a better burner than charcoal.

\section{Acknowledgements}

The authors thank Professor Igbafe, a Professor of chemical engineering and an expert in ecology and environmental engineering for his patriotisms and immense contributions to the realization of this project.

\section{References}

1. Bruce N, Rehfuess E, Mehta S, Hutton G, Smith K (2013) Indoor Air Pollution.

2. Barnes DF, Openshaw K, Smith KR, Van der P (1993) The Design and Diffusion of Improved Cook stoves. The World Bank Research Observer 8: 119-141.

3. Bruce N, Perez-Padilla R, Albalak R (2000) Indoor air pollution in developing countries: a major environmental and public health challenge. Bull World Health Organ 78: 1078-1092.

4. Lindner M, Sohngen B, Joyce L, Price D, Bernier P, et al. (2002) Integrated Forestry Assessments For Climate Change Impacts. Forestry Ecology and Management 162: 117-136.

5. Petersen RAA (2006) Comparison of Avoided Greenhouse Gas Emissions When Using Different Kinds of Wood Energy. Biomass and Bioenergy 30: 605617.

6. Yoshida T, Suzuki H (2010) Current Status of Woody Biomass Utilization in ASEAN Countries. Croatia: InTech Biomass. p: 202.

7. Naciones U (2011) Objetivos de desarrollo del milenio. New York: Departamento de asuntos Económicos y Sociales de laSecretaría de las naciones Unidas.

8. Comisión Mundial de Áreas Protegidas (2000) Áreas Protegidas: Beneficios más allá de las Fronteras. Gland: Unión Mundial para la Naturaleza.

9. Instituto Nacional Estadistica e Informatica (INEI) (2007) Censos Nacionales: $\mathrm{XI}$ de Población y VI de Vivienda. Piura: Instituto Nacional Estadistica e Informatica.

10. Instituto Nacional Estadistica e Informatica (2011) Piura compendio estadistico. Piura: Instituto Nacional Estadistica e Informatica.

11. Fullop V (1989) Guía de cubicación industrial de maderas en trozas. Lima: Proyecto de Desarrollo Industrial Forestal Perú- Canadá

12. Guevara SL, Reyes IP, Bocanegra DL (1993) Evaluación de residuos de aserrio. Folia Amazonica 5: 191-201.

13. Olufemi B, Olalekan J, Oluyinka S (2012) Lumber Recovery Efficiency among Selected Sawmills in Akure, Nigeria. Drvna Industrija 63: 15-18.

14. Eduardo A, Sánchez M, Milagros B, Pasache ME (2014) García Development of Briquettes from Waste Wood (Sawdust) for Use in Low-income Households in Piura, Peru. Proceedings of the World Congress on Engineering 2: 2-4.

15. World Energy Outlook (2006) Energy for Cooking in Developing Countries: OECD/IEA. pp: 419-420.

16. Akii Ibhadode AO, Igbafe AI, Anyata BU (2008) Development of Energy Efficient Solid Fuel for Maximum Emission Reduction and Regular Heating Rate in Fired Heaters. Advanced Materials Research 62-64: 525-532.

17. Pérez-Padilla R, Pérez-Guzmán C, Báez-Saldaña R, Torres-Cruz A (2001) Cooking with biomass stoves and tuberculosis: a case control study. Int $J$ Tuberc Lung Dis 5: 441-447. may be attributed to a repression of some particular minerals within the composite coal that might have possibly been transformed into solid which are embedded in the ash during combustion. The suspension of the minerals from being oxidized maybe attributed to the less release of the pollutant gases. The solution of 1:2 of clay: water, formulated Into composite solid fuels of 1:1 of pure charcoal: clay solution and pure saw dust: clay solution produces the solid fuel-type with the best pollutants emission rates reduction. The addition of the clay content has only contributed in channeling the routes of release of some of the compounds in the fuels to accompany the ash residue rather than as gaseous emissions.

This study has shown a consistent pattern of emission reduction exhibited by the composite charcoal based fuels. The combustion of 